\title{
O diálogo crítico de Ángel Rama e Antonio Candido na perspectiva da hermenêutica de Gadamer*
}

\author{
Ney A. G. Canani**
}

\section{RESUMO}

A distância temporal que nos separa da obra de Candido e Rama permite que os situemos em um período histórico marcado pela consolidação do estado nacional e a crença na modernização como uma força homogeneizadora na sociedade - que já foi concluído e, portanto, pode ser visto como uma unidade. Nos termos de Gadamer, pode-se dizer que essa tradição está suficientemente morta para que possa ser compreendida por inteiro. Por outro lado, os problemas que afetam a crítica literária latino-americana hoje não são tão diferentes daqueles enfrentados por esses autores. Porque os efeitos da tradição de Candido e Rama ainda se fazem sentir, existe interesse em manter vivo um diálogo com eles. Nesse processo, somos convidados a repensar nosso lugar na tradição que nos foi transmitida e reconciliar a estética com a crítica cultural.

Palavras-chave: Hermenêutica. Crítica Literária. Crítica Cultural. Antonio Candido. Ángel Rama.

* O presente artigo baseia-se na tese de doutorado Crítica Estética e Cultural na Tradição Literária Latino-americana. A hermenêutica de Antonio Candido e Ángel Rama, defendida na Universidade Livre de Berlim em 2013 e publicada no portal daquela universidade em 2015. O texto integral da tese está disponível em: <https://refubium.fu-berlin.de/ handle/fub188/4926>. Agradecimentos à Profa. Dra. Ligia Chiappini pelo apoio e incentivo à publicação deste artigo.

** Diplomata de carreira e Professor. Doutor em Filosofia (Doktor der Philosophie), summa cum laude, pela Universidade Livre de Berlim, Mestre em Ciência Política e Licenciado em Letras pela UFRGS, Bacharel em Direito pelo IESB. 


\title{
The critical dialogue between Ángel Rama and Antonio Candido in the perspective of Gadamer's hermeneutics
}

\begin{abstract}
The temporal distance that separates us from the work of Candido and Rama allow us to situate these authors within a historical period - marked by the consolidation of the national state and the belief in modernization as a homogenizing force in society - which has already been ended and can thus be seen as a unity in itself. In Gadamer terms, one can say that this tradition is sufficiently dead so that we can comprehend it as a whole. On the other hand, the problems that affect Latin American criticism today are not so different from the ones tackled by those authors. Because the effects of the tradition of Candido and Rama can still be felt today, there is interest in keeping alive a dialogue with them. In this process, we are invited to rethink our place in the tradition which was handed down to us and reconcile aesthetics with cultural criticism.
\end{abstract}

Keywords: Hermeneutics. Literary Criticism. Cultural Criticism. Antonio Candido. Ángel Rama. 
Das Verstehen ist selber nicht so sehr als eine Handlung der Subjektivität zu denken, sondern als Einrücken in ein Überlieferungsgeschehen, in dem sich Vergangenheit und Gegenwart beständig vermitteln. (Gadamer, 1999 (GW1): p. 295) ${ }^{1}$

Viel hat von Morgen an,

Seit ein Gespräch wir sind und hören voneinander,

Erfahren der Mensch; bald sind wir aber Gesang. (Hölderlin, 2007, p. 64) ${ }^{2}$

Todo encontro com a tradição desafia-nos a reiniciar uma conversa que nunca foi interrompida e da qual participamos desde sempre, uma conversa que somos ("seit ein Gespräch wir sind"), conforme o verso de Hölderlin. Parece pouco provável que se possa dizer algo novo sobre autores como Ángel Rama e Antonio Candido, cuja obra tem passado por processo intenso de revalorização e revisão e sobre a qual já se acumula substanciosa bibliografia. ${ }^{3}$ A presença frequente de Candido e Rama em numerosas antologias e obras coletivas faz supor, ainda, que esses autores já tenham assumido o caráter de "clássicos", o que desencorajaria qualquer releitura inovadora de sua obra. ${ }^{4}$ Porém

1 A compreensão não deve ser vista tanto como um ato de subjetividade, mas como ingresso em uma manifestação da tradição em que passado e presente constantemente se comunicam.

2 Muito desde a manhã, pois que uma conversa somos e um do outro escutamos, aprenderam os homens; logo, porém, seremos canção.

3 Para uma relação bibliográfica bastante abrangente da obra de Candido e sua fortuna crítica, ver Dantas (2002); para a obra de Ángel Rama, ver Blixen; Barros-Lémez (1986).

4 Uma antologia recente, organizada por Ana del Sarto, Alicia Rios e Abril Trigo é o The Latin American Cultural Studies Reader (2004), que inclui artigos de Antonio Candido e Ángel Rama. O Instituto Internacional de Literatura Iberoamericana, da Universidade de Pittsburgh, dedicou um volume da série Críticas a Ángel Rama (Ángel Rama y los Estudios Latinoamericanos), editado por Mabel Moraña (1997) e outro a Antonio Candido (Antonio Candido y los Estudios Latinoamericanos), com 
se a obra clássica é aquela que, conforme uma das definições de Italo Calvino (CALVINO, 1993, p. 11), "nunca terminou de dizer o que tem para dizer", então novas leituras são sempre possíveis e justificáveis. A questão para o intérprete seria apenas encontrar uma mensagem que ainda não tenha sido dita ou, na perspectiva de Hans-Georg Gadamer, encontrar uma nova pergunta para a qual a obra desses autores nos ofereceria uma resposta.

A definição de Calvino (1993) encerra, com efeito, um pressuposto que nos obriga a novas explicações e justificativas. Se a obra clássica nunca terminou de dizer a que veio, é possível que, para diferentes intérpretes e em diferentes épocas, diga coisas diferentes. O sentido da obra, portanto, não está apenas no texto, mas no contexto de sua recepção. É nesse contexto, precisamente, que encontramos a melhor justificativa para voltar a Rama e Candido.

As obras de Ángel Rama e de Antonio Candido têm sido reavaliadas, nas últimas décadas, sob uma perspectiva frequentemente redutora, que insiste em circunscrevê-las a um debate político, em grande medida, já superado. Ou Candido e Rama são exaltados como grandes representantes da tradição ensaística latino-americana - que encontra expoentes em Andrés Bello e Domingos Sarmiento, em língua espanhola, e Gilberto

organização de Raúl Antelo (2001). Juan Poblete (2002) afirma que Ángel Rama "se há convertido ya en un clásico de la cultura latinoamericana", o que se poderia verificar pela inclusão póstuma de seus ensaios na coleção da Biblioteca Ayacucho, que o próprio Rama criou, e pelas leituras que vem sendo feitas da sua obra. O comentário também vale para Candido, que teve ensaios igualmente incluídos na coleção da Biblioteca Ayacucho e cuja obra tem sido submetida a frequentes releituras. No Brasil, os aniversários de 70, 80 e 90 anos de Antonio Candido serviram como pretexto para obras coletivas que abordam diversos aspectos da vida e obra desse autor. 
O diálogo crítico de Ángel Rama e Antonio Candido na perspectiva da hermenêutica de Gadamer

Freyre e Sérgio Buarque de Holanda, em português -, ou são valorizados como precursores de uma ruptura com essa mesma tradição, a qual prenunciaria um novo horizonte temático, teórico e metodológico para os estudos latino-americanos, no âmbito dos chamados "cultural studies". ${ }^{5}$

Nesse processo de reavaliação, frequentemente opera-se uma leitura seletiva desses autores, em especial nos centros de estudos europeus e norte-americanos. Suas últimas obras, mais facilmente aproximadas da perspectiva dos estudos culturais, são privilegiadas em relação às primeiras, normalmente associadas à tradição ensaística latino-americana. Assim, estuda-se sobretudo o Rama de Ciudad Letrada (1984) e Transculturación Narrativa en América Latina [1982]/(2007), negligenciandose o autor de Ruben Darío y el Modernismo [1970]/(1985). No caso de Candido, a recepção fora do Brasil concentrase em obras como O Discurso e a Cidade [1993]/(2010) e, mais especificamente, em ensaios como "Literatura e Subdesenvolvimento" (1970) e, cada vez menos, no clássico Formação da Literatura Brasileira [1959]/(2000). ${ }^{6}$ Trata-se

5 Há autores que estabelecem uma distinção entre os Estudos Culturais que seguem a matriz anglo-saxã, geralmente realizados fora da América Latina, e os estudos culturais latino-americanos, que Mabel Moraña (2006) chama de "cultural critique", os quais derivariam da tradição ensaística latino-americana. Pode-se ver essa distinção como resultado de uma simples diferença de enfoque ou como uma disputa epistemológica e/ ou hermenêutica no interior do campo da Latino-americanística. A própria discussão exaustiva dessas perspectivas e a tentativa de estabelecer e justificar a distinção entre os estudos latino-americanos no Norte e no Sul deixa claro que não se trata, aqui, de mera diferença de enfoque.

6 Roman de La Campa (1999) faz uma revisão da recepção de La Ciudad Letrada, de Ángel Rama, afirmando que a obra tem sido mais citada do que analisada em profundidade. Embora reconheça que o livro guarda muitos elementos de trabalhos anteriores de Rama, acredita que se distingue desses por avançar sobre o discurso pós-estrutural, na incorporação de conceitos de Michel Foucault. Na sua opinião, a obra antecipa os debates teóricos nos Estados Unidos nos anos 1990. Walter Mignolo (1993) também 
de uma leitura que, de um lado ou de outro, supõe uma divisão inconciliável entre a tradição ensaística latino-americana e os Estudos Culturais.

A apropriação seletiva de Rama e Candido sugere, ainda, que algumas obras tenham se tornado ultrapassadas, enquanto outras seriam interessantes somente porque revelariam tendências que mais tarde se tornariam dominantes na crítica literária. Em um caso ou no outro, essa apropriação não apenas é seletiva, como supõe uma negação: as obras de Candido e Rama não diriam nada sobre o presente, não contribuiriam senão de forma indireta para os debates atuais no campo dos Estudos Latinoamericanos. Seja como precursores dos Estudos Culturais ou como representantes da grande tradição crítica, Candido e Rama fariam parte da história da crítica literária latino-americana, fariam parte do passado. Clássico, nessa concepção, significaria talvez historicamente importante, mas não atual, como querem Calvino e Gadamer.

Por trás dessa concepção, esconde-se uma discussão polarizada sobre o papel do intelectual, especialmente latinoamericano, e, mais ainda, sobre a própria função da literatura e dos estudos literários na sociedade, em particular nos países em desenvolvimento. Desde o início, a polarização no campo dos estudos latino-americanos parece estar ligada à crise de uma

ressalta o "pós-estruturalismo" de Rama. Hugo Achugar (1998), por outro lado, situa o grosso da obra de Rama, e inclusive La Ciudad Letrada, na tradição dos pensadores da "Patria Grande" latino-americana. Como uns poucos artigos da vasta obra de Candido foram traduzidos para o espanhol, sua obra permanece em grande medida desconhecida fora do Brasil (Formação..., por exemplo, não foi traduzida). Em 2001, quando se publica Antonio Candido y los Estudios Latinoamericanos, o editor, Raul Antelo, afirmava no prefácio que "Antonio Candido es un crítico aislado", observando que sua obra ensaística recém começava a ser traduzida organicamente ao espanhol. 
O diálogo crítico de Ángel Rama e Antonio Candido na perspectiva da hermenêutica de Gadamer

concepção tradicional dos estudos literários, em que estes se concentravam em encontrar justificativas, estéticas e históricas, para a formação de cânones nacionais e universais. Esta por sua vez se vincula, e às vezes mesmo se confunde, com uma crise na própria avaliação do significado da modernidade e do modernismo para a tradição ocidental, incluindo seus reflexos e contradições na América Latina

No ensaio publicado em 1965, "To Civilize our Gentlemen", George Steiner já comentava a dificuldade dos estudiosos de literatura inglesa em justificar seu campo de estudo. $\mathrm{Na}$ sua avaliação, os estudos literários historicamente teriam encontrado sua fundamentação em três perspectivas dominantes: i) o estudo da literatura clássica seria a base para melhor compreender autores modernos; ii) a literatura seria fundamental para construir a ideia de nação; iii) a literatura representaria uma força moral e edificadora.

Em certa medida, as três perspectivas identificadas por Steiner foram colocadas em questão pelo discurso pós-moderno, que ganhou impulso a partir da década de 70. O estudo dos clássicos passou a ser desvalorizado por sua suposta associação a uma cultura elitista e opressora; a ideia de nação passou a ser contestada por ser alegadamente um instrumento de dominação e supressão das diferenças e, por fim, a literatura, como mais um discurso em um mar de discursos, teria perdido não apenas sua "força moral", como qualquer primazia que pudesse ter como objeto de estudo.

A dificuldade que os estudiosos de literatura inglesa encontravam, em meados dos anos 1960, para justificar seu campo de estudos, também era enfrentada pela crítica literária latino-americana. Nos anos 60 e 70, em especial, esta se deparava com a tarefa de redefinir sua função em face do desafio colocado 
pela chamada nova narrativa, que se tornaria conhecida na Europa e Estados Unidos pelo fenômeno do "boom da literatura latino-americana". Mas o desafio não era apenas compreender as produções literárias que, de forma inédita, estavam chamando a atenção dos pesquisadores no Norte. Como notava Antonio Cornejo Polar, em 1974, a crise epistemológica enfrentada pela crítica literária assumia também o caráter de crise ideológica. Para esse autor, enquanto a crise epistemológica dizia respeito à necessidade de justificar teoricamente o conhecimento produzido pela crítica, a funcional-ideológica partia da constatação de que esse conhecimento, qualquer que fosse, se articularia com uma visão específica sobre os problemas do homem latinoamericano. ${ }^{7}$ A nova literatura, afinal, interpelava a crítica a reinterpretar não somente a tradição literária, mas seus próprios pressupostos epistêmicos e seu compromisso social.

Erin Zivin (2007), referindo-se às dimensões éticas do debate sobre a função dos estudos literários na América Latina, observa que

the last several decades have witnessed a reorientation of the political and a globalization of the cultural in Latin America, shifting literature's function as a homogenizing, citizen-forming institution to a more dispersed, fragmented, and (potentially) democratic and liberating practice. At the same time, and perhaps in response to this cultural shift, the field of Latin American literary studies has expanded to include cultural studies, postcolonial theory, performance studies, gender studies, Africana studies, and subaltern studies, at once expanding and disrupting the boundaries of literature, criticism, and of Latin America itself. (ZIVIN, 2007, p. 1).

7 Apud Martínez (1995. p. 17). 
O diálogo crítico de Ángel Rama e Antonio Candido na perspectiva da hermenêutica de Gadamer

A reorientação de que fala Zivin (2007), resultado da dominação dos cultural studies nos centros de pesquisa norteamericanos e europeus, não foi plenamente incorporada nas universidades da América Latina - quando não foi frontalmente rejeitada. Para muitos estudiosos, a mudança de função da literatura não se deu em direção a uma prática "potencialmente democrática e liberadora", tendo antes levado a uma nova forma de colonização cultural por parte do Norte. Isso teria feito com que a divisão entre uma concepção tradicional de estudos literários e a fragmentação trazida pelos estudos culturais se tornasse também uma clivagem acadêmica entre os latino-americanistas que trabalham no Norte e escrevem, sobretudo, em inglês, e aqueles que trabalham na América Latina e costumam publicar seus trabalhos em espanhol ou português. ${ }^{8}$

Essas duas clivagens, entre cultural studies versus estudos literários tradicionais, de um lado, e crítica literária latinoamericana versus crítica cultural tal como produzida nos centros do Norte, de outro, perpassam as diferentes leituras e apropriações da obra de Antonio Candido e Ángel Rama ao longo das últimas décadas.

Os críticos latino-americanos preocupados em preservar a tradição de pensamento crítico que Beverley (1999) rotula como "neoarielismo" tendem a valorizar Candido e Rama por seu compromisso comuma críticaliteráriaque, conquanto socialmente engajada, não prescinde da tarefa de apontar características e tendências estéticas na literatura latino-americana, explorando também suas origens e vinculações com a literatura ocidental, como um todo. Estudiosos ligados à orientação "culturalista" anglo-saxã, por outro lado, tendem a privilegiar as obras mais

8 Moreiras (2001) analisa, de forma abrangente, as características e as implicações dessa cisão para os Estudos Latino-americanos. 
recentes desses autores, em que a atenção a certas questões valorizadas pela academia norte-americana e europeia, como o status das manifestações culturais populares em relação à "cultura letrada", faz-se notar de forma mais marcante. Nesse processo de ressignificação e reapropriação parcial de Candido e Rama, que reitera a ruptura entre o discurso dos cultural studies e o dos estudos literários, elimina-se qualquer possibilidade de compreender as articulações e convergências entre essas duas perspectivas.

Em um momento em que os debates sobre o status dos estudos literários latino-americanos continuam bastante polarizados e questiona-se, até mesmo, sua relevância em face de agendas de pesquisas que parecem ter dissolvido completamente as distinções usuais entre cultura popular, cultura de massas e cultura letrada - ou entre o nacional, o regional e o global - , pode-se dizer que revisitar a produção crítica de Candido e Rama torna-se necessário como movimento hermenêutico de superação das aporias que têm paralisado a crítica literária latino-americana.

Nesse contexto, recuperar a visão de Hans-Georg Gadamer sobre o processo de compreensão e interpretação, em que as noções de tradição e diálogo ocupam posição central, revelase particularmente produtivo. Na visão de Gadamer, qualquer esforço de interpretação é condicionado pelos efeitos da tradição na qual o sujeito está inserido e da qual nunca consegue libertarse completamente. Interpretar uma obra do passado significa, assim, operar uma espécie de mediação entre o passado e o presente. Nessa mediação, a possibilidade de separar sujeito e objeto ou de suspender os efeitos da história sobre o sujeito, anelos da crítica positivista, é posta em questão. De acordo com a hermenêutica de Gadamer, sempre se interpreta o passado de uma maneira específica, conforme as questões e os interesses 
O diálogo crítico de Ángel Rama e Antonio Candido na perspectiva da hermenêutica de Gadamer

que definem o presente. As questões e interesses que surgem da situação presente, porém, constroem-se em relação contínua com o passado. Passado e presente, afinal, se fundem. Se o intérprete não consegue livrar-se da sua própria subjetividade, menos ainda pode fugir da situação histórica que a condiciona. Sob esse ponto de vista, conclui Gadamer, nenhuma época compreende a tradição melhor do que outra, mas a compreende diferentemente, se a compreende de todo: "Es genügt zu sagen, daß man anders versteht, wenn man überhaupt versteht" (GADAMER, 1999, p. 302). ${ }^{9}$

Cabe resgatar aqui, ainda, a concepção de diálogo de Gadamer, que serve como imagem para explicar a relação do intérprete com o texto, assim como nossa relação com a tradição. O diálogo pressupõe um movimento em que cada parte deseja compreender o outro e está aberta para a possibilidade de rever suas posições. Em uma conversa, que sempre terá sido precedida por outras conversas, não chegamos de mãos vazias. Partimos de uma posição, que conforma nosso próprio horizonte de compreensão. Na medida em que nossa posição muda com a conversa, porém, nosso horizonte se transforma e, eventualmente, funde-se com o do outro. Se Hans-Georg Gadamer está certo quando afirma que interpretar um texto é encontrar a pergunta para a qual o texto é uma resposta, conforme enfatizado por Jauss (1970), então voltar a Candido e Rama significa recuperar um diálogo, de pergunta e resposta, que marcou a tradição crítica na América Latina e que continua nos interpelando a repensar os debates contemporâneos. Nisso consiste, aliás, a atualidade de sua produção.

9 "Basta dizer que entendemos diferentemente, quando entendemos de todo" 
Para alguns analistas, a visão de tradição de Gadamer se ressente de alguns vícios que a tornariam incapaz de captar a dissonância ideológica e a mudança dentro da tradição ou a própria possibilidade de ruptura com a tradição. Embora a autoridade e força que Gadamer confere à tradição no processo de compreensão possa ser vista como tendência conservadora e a resposta de Gadamer à critica de Habermas em certa medida confirma essa avaliação - não há nada na sua hermenêutica que obrigue a seguir essa direção (WARNKE, 2003, p. 137-138).

Vista numa perspectiva dinâmica, a tradição tanto nos condiciona a conservá-la, quanto nos interpela a constantemente recriá-la. Como é impossível escapar aos efeitos da tradição assim como é impossível fugir à história -, o que é visto como ruptura com a tradição, na verdade, só pode ser entendido como mudança dentro da tradição, a partir de elementos já presentes nela.

Assim, a atenção à dimensão da cultura que marca os últimos trabalhos de Antonio Candido e Ángel Rama - ou seja, aqueles mais diretamente associados à perspectiva dos estudos culturais - não necessariamente representa um desvio em relação à orientação das suas primeiras obras, normalmente situadas na perspectiva do ensaio crítico latino-americano, ainda que possa conduzir a uma reavaliação de todo o legado da tradição.

Ao aplicar o conceito de sistema literário, tal como formulado por Candido, à literatura da América Latina, como um todo, Rama é levado a buscar pontos de contato e aproximação entre as diferentes literaturas hispano-americanas e entre estas e a brasileira. Esses pontos de contato serão encontrados, precisamente, na forma como os escritores plasmam em suas obras a cultura na qual estão inseridos. 
O diálogo crítico de Ángel Rama e Antonio Candido na perspectiva da hermenêutica de Gadamer

Falar de cultura, porém, implica uma série de definições. Nenhuma sociedade complexa pode ser abarcada sob apenas uma matriz cultural. A questão da cultura se coloca, assim, como a contraface da questão da identidade. ${ }^{10}$ Se para alguns povos a identidade nacional (ou regional) se construiu sem maiores traumas, no caso da América Latina ela sempre foi campo de embates políticos e sociais, a começar pelos próprios movimentos que levaram à independência. Nesse processo, algumas "culturas" seriam privilegiadas, em detrimento de outras, para conformar as visões dominantes sobre a identidade nacional. Discutir a produção literária sob o ângulo da cultura, portanto, envolve necessariamente debater a questão da identidade nacional (e continental) e, com ela, a da "autonomia" da literatura latino-americana em face das matrizes culturais europeias. A discussão sobre a cultura latino-americana envolve, ainda, pensar a questão da "alta cultura", que se cruza com o problema de como situar a literatura latino-americana em relação à tradição literária ocidental.

Embora o discurso pós-moderno tenha procurado deslegitimar a ideia do nacional como postura essencialista e opressora, não se pode negar que permanece um motor ideológico poderoso que continua pautando o debate político. No caso da América Latina, pode-se perceber a ideia de nação sendo reforçada, ainda hoje, como contrapeso ou antídoto contra o que é percebido como dominação econômica e cultural estrangeira, mesmo que essa ideia perca força com a defesa da integração regional. Além disso, como ocorre em geral com as nações ocidentais, tende a obscurecer a questão das diferenças internas nacionais. Como exceção que confirma a regra, a Bolívia

${ }^{10}$ Para uma revisão da literatura e dos debates sobre a identidade latinoamericana, ver Hale (1997). 
é o único Estado na região que se define como "plurinacional". Mesmo na Europa, em que o ideal integracionista atingiu sua mais forte expressão, em momentos de crise como o atual, voltase a falar em nação e em interesse nacional. A questão nacional está longe de ter sido lançada para os escaninhos da história, portanto. ${ }^{11}$ Reconhecer que permanece atual, porém, não implica dizer que nada mudou na América Latina desde a teoria da dependência. Assim, Neil Larsen defende um novo historicismo na crítica cultural latino-americana, que reconheça que o projeto nacionalista e autonomista dos anos 60 encontrou seus limites e deve ser revisto (LARSEN, 1999).

A opção de Candido e Rama de analisar a produção literária da região com atenção para os processos políticos e sociais levou sua obra a ser classificada, por vezes de forma depreciativa, como socialmente engajada ou sociologizante. ${ }^{12}$ Tais rótulos sugerem uma perspectiva em que o valor estético das obras é visivelmente colocado de lado, quando não completamente ignorado.

Contudo, a crítica de Antonio Candido e Ángel Rama leva em conta não apenas o caráter social do fenômeno literário,

${ }^{11}$ Para uma revisão do debate sobre identidade nacional e nação na América Latina em face da globalização, cf. Grínor Rojo (2006), Globalización e identidades nacionales y postnacionales... de que estamos hablando? Santiago, Lom Ediciones. Para uma discussão sobre a relação entre a crítica literária e a formação nacional na América Latina, ver Ortega (1991).

12 O rótulo de "crítico sociológico" atribuído a Candido é um lugar comum frequentemente reafirmado, mas poucas vezes examinado a fundo, como salienta Ramassote (2008). Entre os autores que ressaltam o compromisso de Candido com a sociologia ou inserem sua obra em uma vertente sociológica da crítica brasileira estão Santiago (1982), Arantes (1992a), Perrone-Moisés (2000), Jackson (2001), Süssekind (2004) e Ramassote (2008). Alguns autores, como Peirano (1991) e Castro (2008), têm procurado destacar a perspectiva antropológica presente na obra de Candido. A obra de Rama não tem sido objeto de classificações tão rígidas, mas, de maneira geral, salienta-se a perspectiva sociológica ou cultural do autor. 
O diálogo crítico de Ángel Rama e Antonio Candido na perspectiva da hermenêutica de Gadamer

mas também sua dimensão estética, a partir de suas concepções sobre o valor artístico, e não meramente documental ou representativo, da obra literária. O próprio conceito de sistema literário, visto como âncora de uma abordagem sociológica da literatura, permitiu articular uma concepção de valor artístico que, se bem estará imbricada na tradição, não elide a questão da autonomia da obra. Nessa perspectiva, a existência de um público consumidor de literatura nativo, indispensável para a formação do sistema, não tem significado somente social, pois, como ressalta Candido, ao menos nos seus períodos formativos, a produção literária responderá aos apelos estéticos desse público e terá uma qualidade compatível com seus níveis de exigência. Como os teóricos da recepção têm defendido, a atenção para o público receptor da literatura permite efetivamente superar a dicotomia entre função social da obra e valor estético (JAUSS, 1970, p. 177).

Na concepção de Candido, está implícita ainda a avaliação de que o valor estético dos textos das literaturas nacionais só poderá ser avaliado a partir de um confronto com os textos da tradição ocidental, na qual o sistema nacional estaria inserido ou com a qual se relacionaria de forma mais ou menos tensa. A questão da autonomia da literatura nacional (ou continental) não apresenta relevância apenas política ou ideológica, portanto, como muitas vezes se infere, mas também estético-cultural.

Questão conexa com a da autonomia da literatura produzida na América Hispânica é a da relação da literatura hispano-americana com a brasileira. Se o conceito de sistema literário, tomado de empréstimo a Candido, pode ser aplicado à discussão da literatura hispano-americana, isso não significa que deva ou possa englobar todas as literaturas produzidas na 
América Latina. As relações de afinidade estética ou social entre textos produzidos em diferentes partes do continente americano são, porém, demasiadamente evidentes para que uma conexão sistêmica e/ou cultural não seja explorada.

Desde muito cedo, Candido e Rama assumiram esse desafio, buscando identificar problemas e tendências comuns às produções literárias da América Latina. Essa ambiciosa tarefa exigiu o desenvolvimento de categorias de análise suficientemente amplas para dar conta da diversidade da literatura regional, mas ao mesmo tempo delimitadas o bastante para permitirem a caracterização da especificidade, como fenômeno cultural, dessa literatura. O critério mais simples para a integração da literatura latino-americana, a língua, deixaria de fora do sistema, forçosamente, a literatura brasileira, e tornaria difícil a separação da literatura latino-americana da matriz espanhola. Além disso, faria supor uma unidade linguística que turvaria a visão dos analistas para a percepção de que "los comportamientos lingüisticos en un mismo punto de la historia pueden ser diametralmente distintos, lo que apunta a estratos contíguos y superpuestos." (RAMA, 2006, p. 99-100).

Embora Rama, em La Ciudad Letrada Rama (1984), trace um percurso distinto do de Candido em Formação da Literatura Brasileira (2000), orienta-se por princípios semelhantes aos do crítico brasileiro. Assim como Candido, está preocupado em descrever em que condições pode-se desenvolver um sistema literário, mas, no seu caso, o foco da atenção não é um país específico, mas a América Latina como um todo. ${ }^{13}$ Rama (1984) amplia o interesse de Candido pelo corpus literário do período colonial, porém, ao analisar a formação de instituições e atores

${ }^{13}$ Rojo (2008) mostra como a preocupação inicial de Rama com tradição literária nacional uruguaia, a partir do conceito de sistema de Candido, vai progressivamente se expandindo até englobar todo o continente sulamericano. 
O diálogo crítico de Ángel Rama e Antonio Candido na perspectiva da hermenêutica de Gadamer

que levaram à formação de uma cultura letrada na região, base para a constituição do sistema literário. Rama coloca-se, assim, um programa de pesquisa ao mesmo tempo mais fundamental e mais amplo do que o de Candido (1959), não concebendo o sistema literário como tão-somente um conjunto de relações entre autor-obra-público em um dado momento histórico, mas como parte de um sistema maior, que é a própria cultura letrada. Amplia-se, assim, o leque de relações relevantes que influenciam a produção literária, e caberia ao crítico levá-lo em consideração.

O problema da valoração artística dos textos literários, de toda forma, persiste. A identificação dos mecanismos por meio dos quais se forma a cultura letrada define elementos do contexto em que as obras literárias serão produzidas e recebidas, bem como põe em relevo a função da literatura nesse contexto. Fornece, assim, elementos para o que poderia ser uma análise do valor estético da literatura nos marcos da teoria da recepção. Pouco nos diz, entretanto, sobre a forma como o texto estruturase, internamente, na relação com a cultura. Essa questão é explorada por Rama em Transculturación Narrativa en América Latina (2007). Nessa obra, em que analisa a literatura de José Maria Arguedas, o crítico uruguaio penetra na tessitura do texto para descobrir o mecanismo cultural que the deu origem, avançando sobre um terreno já trilhado por Candido em Literatura e Sociedade [1965]/(2000) e nos vários ensaios que seriam agrupados em Educação pela Noite [1987]/(2006) e O Discurso e a Cidade (2010).

Parece haver, assim, uma convergência fundamental entre as agendas de pesquisa de Ángel Rama e Antonio Candido. Enquanto o primeiro procura traçar um programa geral para estudar a literatura na América Latina e procura fundamentar 
teoricamente esse programa com base numa concepção culturalista do fenômeno literário, Antonio Candido desenvolve um modelo analítico para pensar a literatura brasileira que, embora não parta de uma concepção estritamente culturalista da literatura, reconhece sua conexão com a cultura e explora as consequências dessa ligação.

Embora gestado para pensar a literatura brasileira, o modelo de Candido acaba sendo instrumental para analisar toda a literatura da região. ${ }^{14}$ Questões caras a Candido como a relação entre a sociedade e a literatura, ou entre a estrutura do texto e a realidade, por sua vez, serão também problematizadas por Rama na análise da literatura latino-americana, perpassando, como um subtexto, as discussões sobre a tradição e a vanguarda.

Os dois autores se aproximam, assim, ao analisar as relações entre literatura e sociedade, ao buscar identificar a especificidade da literatura que estudam vis-à-vis a literatura europeia, e ao procurar elaborar um modelo explicativo próprio para analisar a produção literária local, o que não deixa de conformar uma hermenêutica própria. Ao empreender esforço de buscar pontos de contato e aproximação entre as literaturas em espanhol da América Latina e entre estas e a brasileira, Ángel Rama demonstra interesse em não apenas problematizar as noções instituídas de fronteira linguística e cultural na região, mas também discutir os procedimentos da crítica literária latino-americana. Com o conceito de transculturação, por sua vez, mergulha no estudo da relação entre a estrutura do texto e a cultura.

${ }^{14}$ Garramuño e Amante (2001) defendem a tese de que a obra de Candido, embora tendo por base a literatura brasileira, fornece conceitos úteis para pensar a literatura latinoamericana como um todo. Ligia Chiappini Moraes Leite, em "Ángel Rama e Antonio Candido: teoria, utopia e antropologia" conclui que isso explica a influência de Candido sobre o crítico uruguaio. 
O diálogo crítico de Ángel Rama e Antonio Candido na perspectiva da hermenêutica de Gadamer

A conversa entre Ángel Rama e Antonio Candido é uma via de mão dupla, porém, e se o crítico uruguaio desenvolve obra cada vez mais sofisticada e variada, do ponto de vista temático, pelo contato com as investigações do brasileiro, este também amplia seus horizontes analíticos e seus interesses de pesquisa a partir do contato com a obra do colega e amigo. Nos ensaios de Candido "Literatura de Dois Gumes" (1966) e "Literatura e Subdesenvolvimento" (1970) ${ }^{15}$, temas explorados preliminarmente por Rama, como a relação entre a alta e a baixa cultura, ou entre a literatura e as instituições sociais da cidade letrada, são incorporados à análise. O ensaio do brasileiro desgarra-se, por fim, dos estudos de autor ou de obras específicas, para os amplos panoramas que sempre fascinaram Rama.

A relação entre Ángel Rama e Antonio Candido tem sido estudada, predominantemente, sob o ponto de vista das influências e, sobretudo, na direção Candido-Rama. A aproximação entre os autores se daria inicialmente pelo uso de conceitos comuns e aprofundar-se-ia com o contato pessoal e a troca de correspondência, mantida ao longo de vários anos. Uma primeira tentativa de mapear essas influências foi realizada em 2001, com a publicação de Antonio Candido y los Estudios Latinoamericanos, pelo Instituto Internacional de Literatura Iberoamericana, da Universidade de Pittsburgh (EUA). Nessa obra, republica-se uma resenha de Ángel Rama sobre Formação..., que permite identificar na obra de Cândido a gênese de muitos conceitos utilizados pelo crítico uruguaio. A partir da análise dessa resenha e da correspondência entre os dois críticos, Pablo Rocca (2001, p. 53) conclui que "en el terreno

15 Reunidos em Candido (2006). 
profesional donde comienza Candido concluye Rama; en la visión integradora donde comienza Rama continúa Candido". Ao retraçar o caminho das influências, Rocca adverte, porém, que "el universo de las ideas no admite divisiones tan rígidas. Hay, en el plano de la reflexión latinoamericana y cultural de los dos, un punto de corte, un nudo en el que las genealogías se confunden y las ideas se entrecruzan y fertilizan." (ROCCA, 2001, p. 53). Essa análise é aprofundada por Rocca (2006) em capítulo de sua tese de doutoramento, Ángel Rama, Emir Rodriguez Monegal y el Brasil: dos caras de un Proyecto Latinoamericano. A relação Rama-Candido também é analisada por Pia Paganelli (2010), que se refere à construção de uma linguagem crítica de cunho latino-americano a partir do diálogo desses autores, e de Lívia Reis (2008), que aborda o diálogo dos dois críticos como parte de um processo de contatos no sul que inclui a estada de Alfonso Reyes no Brasil e os contatos entre Cecília Meirelles e Gabriela Mistral. Grinor Rojo (2008) se concentra nos conceitos de sistema e tradição, mostrando como as concepções teóricas que Candido utiliza para analisar a literatura brasileira serviram de base para que Rama desenvolvesse a noção de um sistema literário latino-americano. Ligia Chiappini, por sua vez, em "Ángel Rama e Antonio Candido: teoria, utopia e antropologia", explora a tese de que a proximidade entre os dois críticos decorreria da adoção de uma mesma atitude, uma mesma perspectiva, que estaria ligada às suas concepções sobre a relação entre cultura e literatura, lembrando a forte influência da antropologia na formação de Antonio Candido.

O diálogo entre Candido e Rama ganha vida e atualidade porque aporta perspectivas nem sempre coincidentes, mas em geral inovadoras, para problemas que interessam a crítica literária produzida na América Latina hoje. A distância temporal 
O diálogo crítico de Ángel Rama e Antonio Candido na perspectiva da hermenêutica de Gadamer

que hoje nos separa da produção de Candido e Rama da década de 70 permite-nos situá-la dentro de um período - de afirmação do Estado nacional e de crença na força homogeneizadora da modernização - que já foi concluído e que, portanto, pode ser visto como uma unidade. Sabendo hoje que o projeto de modernização social da América Latina, tal como concebido naquela época, não se realizou, podemos avaliar as produções que partiam desse pressuposto de forma mais crítica (pois esse pressuposto não é mais o nosso) do que na época em que vieram à luz. Em termos gadamerianos, aquela tradição está suficientemente morta para que possamos compreendê-la de forma integral. Se temos interesse em voltar ao discurso daquela época, porém, é porque as questões que nos afetam hoje não estão tão distantes daquela tradição de modo a não nos dizerem mais nada. Ao contrário, é porque seus efeitos ainda se fazem presentes hoje, estão vivos, que temos interesse em voltar a ela. Assim, voltamos a ela como buscamos o diálogo com um Outro que nos interpela a repensar nossa tradição, como algo que se formou a partir de uma herança, que nos foi transmitida. Essa tradição, afinal, está viva, e reconhecemos que estamos ligados a ela.

Ler Candido e Rama em uma perspectiva hermenêutica significa, assim, reconhecer que voltamos a eles a partir de um olhar do presente, que se distingue daquele contemporâneo a suas produções - ou seja, que mantém um distanciamento histórico em relação a ele - mas que o fazemos não simplesmente para reconhecer sua alteridade, mas para, pondo-a em relevo, questionar nossos próprios pressupostos.

É difícil obter uma visão sintética das concepções de Gadamer sobre a interpretação da obra literária. Em certa medida, todo o seu sistema filosófico deriva de uma visão particular sobre a obra de arte e sua interpretação, a partir da qual se desenvolve 
uma teoria abrangente sobre as condições e as características do processo de compreensão/interpretação, o que define, de forma decisiva, o nosso ser-estar (Dasein) no mundo. As concepções de Gadamer sobre a objetividade e a subjetividade do intérprete permitem abordar alguns axiomas do pensamento pós-moderno sob nova luz, ao mesmo tempo em que colocam o fazer crítico de Candido e Rama em nova moldura, que ressalta a vitalidade de seu pensamento.

Se a tradição é condição de existência da literatura como fenômeno cultural e essa tradição depende da continuidade criadora, assim como da existência de uma relação estável entre autor, obra e público, o crítico participaria da tradição tanto por ajudar a conformar o público quanto por orientar o criador. Do ponto de vista da cidade letrada, contribuiria para a formação da tradição literária ao dar sentido para aquilo que, de outra forma, poderia ser visto como simples sucessão desconectada de obras no tempo. ${ }^{16}$ Ainda que essa tradição, que estabelece o cânone, difundido e preservado ao longo do tempo pelo sistema de ensino, não seja a única dimensão relevante da cultura latino-americana e, portanto, não desfrute de nenhum privilégio ontológico, é aquela na qual a literatura culta é produzida e recebida.

${ }^{16}$ Pode-se adotar aqui duas perspectivas. Ou as obras não possuem necessariamente um vínculo entre si e a criação da tradição seria mais obra do crítico (e do sistema de ensino) do que dos escritores, ou a tradição surge da influência entre gerações de autores e da autoconsciência dos escritores sobre essa influência, bem como de sua consciência sobre seu papel como continuadores ou contestadores de uma tradição (casos em que, de uma forma ou de outra, a tradição é reafirmada). A noção de tradição, de Gadamer, parece favorecer mais a segunda, embora não exclua a primeira. Essa é também a posição defendida por Candido e Rama na análise da tradição latino-americana. Em La Ciudad Letrada, porém, Rama atenta para processos de construção e preservação de poder em que as duas perspectivas estão presentes. 
O diálogo crítico de Ángel Rama e Antonio Candido na perspectiva da hermenêutica de Gadamer

De um ponto de vista teórico, a posição de que a crítica é uma atividade marcada pela sua condição histórica e deve estar atenta aos problemas do seu tempo pode ser vista como decorrência da forma como Candido e Rama interpretam a relação entre literatura e sociedade no âmbito do sistema. Nas concepções de Candido e Rama sobre o fazer crítico há, contudo, mais do que um simples reflexo de suas concepções sobre os efeitos sociais da literatura e da crítica, uma postura de engajamento em relação aos problemas de sua época.

Aidentificação de um compromisso social na crítica literária de Candido e Rama não é descabida, mas, sem qualificações, pode ser enganadora. O engajamento social desses autores é convergente com sua visão sobre a função da literatura e o papel do intelectual na sociedade. Não se revela na escolha de autores e temas a serem investigados, porém, e tampouco se vê marcado, de forma simplista, pela aplicação de uma visão de mundo determinista ao objeto de análise. Dá-se, primeiramente, pela preocupação em pensar como se desenvolve o sistema literário em um contexto colonial ou pós-colonial e em que medida é possível formar-se uma literatura com características próprias na região.

Essa preocupação, por sua vez, situa-se no contexto de um pensamento crítico sobre a América Latina e sobre o subdesenvolvimento, ou seja, no âmbito de uma tradição, a qual envolveu os intelectuais de um ponto de vista existencial (mais do que simplesmente teórico). ${ }^{17}$

A atenção que a obra crítica desses autores sempre conferiu à relação entre literatura, cultura e sociedade não decorre, simplesmente, de mera postura intelectual, mas de

${ }_{17}$ Para análises informadas sob essa perspectiva, ver, no caso de Candido, Aguiar (1999) e Pedrosa (1994). 
um compromisso, logo assumido, com a transformação da sociedade em que viviam. Isso não significa que as posições teóricas e analíticas que assumiram ao longo dos anos só tenham interesse histórico ou tenham, sobretudo, interesse histórico. Essa constatação tampouco deve levar a que se negligencie seus primeiros trabalhos, sob o argumento de que suas análises seriam datadas.

A utilização de uma abordagem hermenêutica gadameriana é útil, nesse sentido, para chamar a atenção de que, se as posições de Candido e Rama são afetadas pela história e refletem os preconceitos e aspirações de sua época, também as nossas não podem ser vistas fora da história. Assim, o interesse que temos em voltar a Candido e Rama deve ser visto como situado em uma perspectiva histórica em que reconhecemos que nossas posições não se formaram - e não podem se formar - voltando às costas para a tradição, mas reconhecendo seu efeito sobre nós, o que não significa que essa tradição não possa ser repensada.

Ter presente a história da América Latina e seus condicionantes na interpretação de Candido e Rama não deve implicar que se veja sua obra somente como testemunho de uma época. Uma das mais importantes contribuições de Gadamer terá sido mostrar, aliás, que, se nossa consciência é afetada pela história (como transparece no conceito de "wirkungsgeschichtliches Bewußtsein") ${ }^{18}$, isso vale tanto para a leitura histórica da importância de Candido e Rama quanto para nossa própria releitura desses autores. $\mathrm{O}$ encontro com a tradição é um evento em que a verdade aparece, se constrói e se reconstrói. A preocupação de Candido e Rama com temas sociais não pode deixar de ser vista, assim, como sendo também uma tomada de

${ }^{18}$ [em grosseira tradução, "consciência afetada/efetuada historicamente"] 
O diálogo crítico de Ángel Rama e Antonio Candido na perspectiva da hermenêutica de Gadamer

posição em um embate ideológico. Esse embate, por sua vez, só faz sentido porque encontra justificativa em uma realidade vista como problemática e na qual os intelectuais podem ser agentes críticos de transformação da sociedade.

Noções como autonomia da literatura e (in)dependência cultural, modernização e modernismo, literatura como expressão cultural e/ou arte, só assumem o primeiro plano de seus trabalhos porque respondem a anseios e a transformações concretas da sociedade em que estão inseridos. Se esses desafios ainda não foram completamente superados - e é nossa avaliação que não foram e talvez nunca sejam, embora vivamos em um mundo diferente daquele em que começaram a produzir - então justifica-se plenamente voltar a eles. Olhar para a tradição crítica de Candido e Rama é voltar-se para a história intelectual da América Latina no século 20, que continua a reivindicar nossa interpretação.

Nessa tradição, a questão nacional é que dá sentido e coesão ao tratamento de vários problemas. Se abandonarmos a preocupação com a autonomia da literatura, que surge em um contexto de nacionalismo literário, definir o momento em que surge um "sistema literário" nacional, assim como descrever suas características estruturadoras, perde a relevância. Da mesma forma, a relação entre literatura e cultura só é vista como algo problemático a ser analisado e descrito, e não como algo dado, no momento em que a preservação de determinada cultura pela literatura passa a ser importante para a formação da identidade nacional.

Por esse motivo, não se costuma discutir a forma como a literatura francesa ou inglesa representa a cultura de seus países, mas essa questão é recorrente na análise das literaturas latino- 
americanas (e pós-coloniais, em um sentido mais amplo). Em certo sentido, a atenção à relação entre a cultura e a literatura se justifica pela importância da questão da identidade para a América Latina. Mas essa atenção não deixa de encerrar, também, uma distorção, pois enquanto as literaturas nacionais francesas e inglesas, para ficar nesse exemplo, são destacadas pelo seu valor artístico, as latino-americanas e periféricas, de modo geral, são vistas quase sempre no seu papel documental.

A noção de que a literatura possa ser vista como unidade e permanência, ou seja, como tradição, desafia alguns paradigmas correntes dos Estudos Culturais, que tendem a enfatizar a descontinuidade, a dispersão e a fragmentação da produção cultural, que só seria vista como contínua e homogênea por um esforço de supressão das diferenças.

A perspectiva de continuidade da tradição trazida por Candido é refinada em Rama, dando lugar a uma concepção de cultura em que a diversidade é reconhecida como um traço essencial da experiência latino-americana. Apesar de reconhecida em sua diversidade, contudo, a cultura continuará sendo invocada como elemento agregador que fundamenta não apenas a identidade nacional, como a identidade latinoamericana.

Na ideia de tradição está imbricada, sem dúvida, a noção de relação com o passado, enquanto a ruptura modernista nega essa relação. A discussão se torna mais complexa na medida em que se levam em conta diferentes temporalidades agindo sobre o presente, algo só abordado indiretamente por Gadamer, assim como a noção de diferentes simultaneidades, entendida aqui como a possível coexistência de diferentes "tradições", ou seja, de diferentes apropriações de um mesmo passado por diferentes grupos que o interpretam de forma distinta. 
O diálogo crítico de Ángel Rama e Antonio Candido na perspectiva da hermenêutica de Gadamer

Essa qualificação é importante porque, quando se afirma a especificidade da literatura latino-americana, sua diferença em relação à matriz ocidental, costuma-se fazê-lo como se a literatura pós-colonial não pudesse ser avaliada a partir dos mesmos critérios da literatura ocidental e, consequentemente, nunca pudesse tornar-se "canônica". Ao contrário, quando uma obra literária de um país em desenvolvimento é reconhecida fora da região e um autor latino-americano recebe um prêmio Nobel, por exemplo, essa costuma ser desqualificada como se seu ingresso virtual no cânone ocidental significasse o desaparecimento da diferença que lhe daria valor. Fica evidenciado, nesse caso, que a valorização da obra não decorria do reconhecimento de seu valor como literatura, mas de sua importância social ou cultural, de sua capacidade de "representar" a realidade local, a qual seria de alguma forma mitigada com sua pretensão universal. Nessa reafirmação da diferença, esquece-se que a literatura é arte e, como tal, tem um poder que independe de sua capacidade de representar o local e que, inclusive, como Candido bem reconhece, costuma ser mais bem-sucedida quando não tem a preocupação obsessiva de representar.

Contudo, em um meio que carece de legitimação e representação, a função representativa da obra literária dificilmente poderá ser negligenciada. Como Candido notou, se a literatura brasileira se constituiu como expressão de um desejo dos brasileiros de ter literatura, é natural que seja vista também como materialização, ainda que necessariamente imperfeita, desse desejo. Analisar a obra sob esse ponto de vista, inclusive nas suas conexões sociais, é necessário porque essa dimensão de alguma forma terá sido incorporada na estrutura da obra. Isso não significa, porém, que a obra não tenha valor além disso. É 
sobretudo esse valor, propriamente literário, que o crítico deveria buscar, um valor que poderá ser auferido na exata medida em que a obra não tiver função apenas representacional. Nenhum crítico sério valoriza Shakespeare ou Goethe apenas pela capacidade desses autores de representar a sociedade de sua época. Nenhum crítico latino-americano sério deveria, da mesma forma, julgar a literatura produzida na América Latina apenas pelo seu valor representativo. Candido tinha isso muito claro quando afirmou, em Formação..., que os brasileiros deveriam amar sua literatura porque essa é a única que os representa, mas que seu valor universal não decorre disso. Assim, se, ao se debruçar sobre a literatura latino-americana, o crítico não poderá se furtar à consideração do desejo de autonomia que, do ponto de vista social, afeta a constituição dessas literaturas, isso não implica que essa será a medida da sua qualidade estética. Se estamos aqui diante de duas formas de análise, uma que privilegia o estético e outra que privilegia o cultural, ambas estão relacionadas a partir do vínculo obrigatório que o uso do conceito de tradição estabelece entre cultura, sistema e literatura.

A questão da formação dos sistemas literários nacionais e de um sistema literário latino-americano ganha importância, porque não apenas permite discutir a relação entre a cultura e a literatura (ou a literatura e a sociedade), mas também porque equaciona a questão do desejo de autonomia latino-americano e a tradição ocidental.

Ora, o principal ponto de confluência da crítica de Candido e Rama e a hermenêutica de Gadamer se encontra precisamente na forma como concebem a tradição. Tanto Candido quanto Rama souberam construir uma visão sobre a literatura e a cultura latinoamericana que não recusa a tradição, mas estabelece um diálogo com ela. A revalorização da tradição e o reconhecimento da sua importância para a constituição da literatura latino-americana 
O diálogo crítico de Ángel Rama e Antonio Candido na perspectiva da hermenêutica de Gadamer

permite unir em uma mesma mirada os eixos da cultura, estética e interpretação presentes em suas obras e constitui justificava especial para abordá-las a partir dessa perspectiva.

Deve-se reconhecer, contudo, que a tradição para Candido e Rama frequentemente assumiu contornos mais difusos do que o conceito de Gadamer. A tradição ora representava a cultura das metrópoles culturais e a ligação com o ocidente, ora a negação dessa ligação e a busca de autonomia a partir da revalorização das tradições locais. Se Candido sempre valorizou a ligação das literaturas latino-americanas com a tradição ocidental, questionando a viabilidade e a validade do desejo de autonomia, Rama foi mais atento para os elementos de tensão na relação da tradição ocidental com as culturas locais. Entretanto, a fórmula encontrada por Rama para descrever essa tensão e a possibilidade de resolver o conflito entre a modernidade ocidental e as culturas tradicionais, sintetizada no conceito de "transculturação", mostra que a tradição latino-americana é capaz de se reinventar no diálogo com o ocidente e, em um processo de constante troca, pode mesmo oferecer contribuição inestimável e original para a tradição ocidental, que é afinal também a sua tradição.

\section{Referências}

ACHUGAR, H. Prólogo a La Ciudad Letrada. In: RAMA, A. La Ciudad Letrada. Montevideo: Arca, 1998.

AGUiAR, F. (Ed.). Antônio Candido - Pensamento e Militância. São Paulo: Fundação Perseu Abramo, 1999.

AGUiAR, F.; VASCONCELOS, S. G. (Ed.) Ángel Rama: literatura e cultura na América Latina. São Paulo: Edusp, 2000. 
ANTELO, R. (Ed.). Antonio Candido y los Estudios Latinoamericanos. Pittsburgh, Instituto Internacional de Literatura Iberoamericana, 2001.

BEVERLEY, J. Subalternity and representation: Arguments in cultural Theory. Durham and London: Duke University Press, 1999.

BLIXEN, C.; BARROS-LÉMEZ, A. Cronologia y Bibliografia de Ángel Rama. Montevideo: Arca, 1986.

CALVINO, I. Por que ler os clássicos? São Paulo: Companhia das Letras, 1993.

CAMPA, R. d. 1. Latinamericanism. Minnesota: University of Minnesota Press, 1999.

CANDIDO, A. Formação da Literatura Brasileira. Belo Horizonte-Rio de Janeiro: Editora Itatiaia, 2000. 2 v.

CANDIDO, A. Literatura e Sociedade. São Paulo: Publifolha, 2000.

CANDIDO, A. A Educação pela Noite. Rio de Janeiro: Ouro sobre Azul, 2006.

CANDIDO, A. O Discurso e a Cidade. Rio de Janeiro: Ouro sobre Azul, 2010.

CASTRO, R. O. d. A Antropologia como Fundamento teórico da crítica literária: o caso de Antonio Candido. In: Reunião Brasileira de Antropologia, 26., 2008, Porto Seguro. Anais [...]. CASTRO-KLAREN, S. (Ed.) A Companion to Latin American Literature and Culture. Oxford, Blackwell, 2008.

CHIAPPINI MORAES LEITE, L. Ángel Rama e Antonio Candido: teoria, utopia e antropologia. Berlin, Freie Universität Berlin. Mimeografado.

DANTAS, V. Bibliografia de Antonio Candido. São Paulo: Duas Cidades/Editora 34, 2002. 
O diálogo crítico de Ángel Rama e Antonio Candido na perspectiva da hermenêutica de Gadamer

GADAMER, H.-G. Gesammelte Werke (10 Bande). Band 1. Tübingen: J.C.B Mohr, 1999.

GARRAMUÑO, F.; Amante, A. Partir de Candido. In: ANTELO, R. Antonio Candido y los Estudios Latinoamericanos. Pittsburgh: Instituto Internacional de Literatura Iberoamericana, 2001.

HALE, C. Cultural Politics of Identity in Latin American. Review of Anthropology. v. 26, p. 567-590, 1997.

HÖLDERLIN, F. Poems of Friedrich Hölderlin. Selected and translated by James Mitchell. Ithuriel's Spear, San Francisco, 2007.

LARSEN, N. Fin de la Historia, o una historia de fines? Hacia un "Segundo historicismo" en la crítica literaria latinoamericanista. Revista de Crítica Literaria Latinoamericana, v. 25, n. 50, p.87-90, 1999.

MARTÍNEZ, A. Metacrítica. Problemas de Historia de la crítica literária en Hispanoamérica y Brasil. Mérida: Universidade de los Andes, 1995.

MIGNOLO, W. Colonial and Postcolonial Discourse: Cultural Critique or Academic Colonialism? Latin American Research Review, v. 28, n. 3, p. 120-134, 1993.

MORAÑA, M., (Ed.) Ángel Rama y los Estudios Latinoamericanos. Pittsburgh: Instituto Internacional de Literatura Iberoamericana,1997.

MOREIRAS, A. The Exhaustion of Difference: The Politics of Latin American Cultural Studies. [S. l.] Duke University Press, 2001. 
ORTEGA, J. Discurso Crítico y Formación Nacional. Revista de Crítica Literaria Latinoamericana, año 17, n. 33, p. 95102, 1991.

PAGANELLI, P. La relación intelectual entre Ángel Rama y Antonio Candido: la constitución de un lenguaje crítico de cuño latinoamericano. Antíteses, v. 3, n. 5, p. 247-267, 2010.

PEDROSA, C. Antonio Candido: A Palavra Empenhada. São Paulo: Edusp, 1994.

PEIRANO, M. G. S. Uma Antropologia no Plural - Três Experiências Contemporâneas. Brasília, Editora da UnB, 1992. POBLETE, J., (Ed.) Trayectoria crítica de Ángel Rama: la dialéctiva de la producción cultural entre autores y públicos. Estudios y Otras Prácticas Intelectuales Latinoamericanas en Cultura y Poder. Caracas: Consejo Latinoamericano de Ciencias Sociales (CLACSO) y CEAP, FACES, Universidad Central de Venezuela, 2002.

RAMA, A. 10 Problemas para EI Narrador Latinoamericano. Caracas: Sintesis Dosmil, 1972.

RAMA, A. La Ciudad Letrada. Hanover: Ediciones del Norte, 1984.

RAMA, A. Ruben Dario y el modernismo. Caracas: Alfadil Ediciones, 1985.

RAMA, A. Transculturación Narrativa en América Latina. Montevideo: Fundación Ángel Rama, 2007.

RAMASSOTE, R. M. A Formação dos Desconfiados: Antonio Candido e a Crítica Literária Acadêmica (1961-1978). 2006. Dissertação (Mestrado em Antropologia) - Universidade Estadual de Campinas, Departamento de Antropologia Social do Instituto de Filosofia e Ciências Humanas, Campinas. 177p. 
O diálogo crítico de Ángel Rama e Antonio Candido na perspectiva da hermenêutica de Gadamer

RAMASSOTE, R. M. A sociologia clandestina de Antonio Candido. Tempo Social, revista de sociologia da USP, v. 20 n. 1, p. 219-237, 2008

ROCCA, P. 35 Años en Marcha. Montevideo: Division Cultura de la IMM, 1992.

ROCCA, P. Notas sobre el diálogo intelectual Rama/ Candido. In: ANTELO, R. Antonio Candido y los Estudios Latinoamericanos. Pittsburgh: Instituto Internacional de Literatura Iberoamericana, 2001.

ROCCA, P. Dialéctica de la revolución (Notas sobre una polémica entre Ángel Rama y Emir Rodríguez Monegal). Revista del Centro Interdisciplinario de Literatura Hispanoamericana, año 6, p. 111-124, 2004.

ROCCA, P. Ángel Rama, Emir Rodriguez Monegal y el Brasil: dos caras de un Proyecto Latinoamericano. Faculdade de Filosofia, Letras e Ciências Humanas. São Paulo: Universidade de São Paulo, 2006.

ROJO, G. Ángel Rama, Antonio Candido y los conceptos de sistema y tradición en la teoría crítica latinoamericana moderna. Discursos/prácticas, n. 2, sem. 1, p. 79-99, 2008.

SARTO, A. d., RÍOS, A.; TRIGO, Abril (Eds.) The Latin American Cultural Reader. Durham and London, Duke University Press, 2004.

STEINER, G. George Steiner: a reader. Oxford, Oxford University Press, 1987.

SÜSSEKIND, F. Literatura e vida literária. Belo Horizonte: Editora da UFMG, 2004.

WARNKE, G. Gadamer - Hermeneutics, Tradition and Reason. Cambridge: Polity Press, 2003.

ZIVIN, E. G., (Ed.) The ethics of Latin American literary criticism: reading otherwise. New York: Palgrave Macmillan, 2007. 